\title{
Pediatrics pharmacovigilance: need of a new sub-unit
}

\author{
Rakesh C. Chaurasia*
}

Department of Pharmacology, M.L.N. Medical College, Allahabad 211002, India

Received: 4 September 2012

Accepted: 15 September 2012

\section{*Correspondence to:}

Dr. Rakesh Chandra Chaurasia, E-mail: drrakesh65@rediffmail.com

\begin{abstract}
Pharmacovigilance is a new discipline of pharmacology concerned with adverse drug reaction (ADR) monitoring. Being an emerging section, it gains widespread global popularity within a short span of time. Pediatrics is very special branch of medical science deals with innocent aspect of growing life. As most of their body physiology are varies in accordance to age, therefore ADRs detection needs special attention.
\end{abstract}

Keywords: Adverse Drug Reactions, Pharmacoenvironmentology, WHOEMLc

\section{WHAT IS PHAMACOVIGILANCE?}

Pharmacovigilance (PV) is the science and activities relating to detection, assessment, understanding, observation and prevention of adverse effects of medicine. PV is science of collecting, monitoring, researching, assessing and evaluating the information from healthcare provider on adverse effect of medication and biological products etc. ${ }^{1}$ Together with WHO collaborating Center of International Drug Monitoring, Uppsala, WHO promote it at country level. At the end of 2011, over 134 countries were part of WHO-PV programme. $^{2}$

\section{PHARMACOVIGILANCE IN INDIA}

The National Pharmacovigilance Programme (NPP) in India was started in November 2004. It is conducted and overseen by Central Drugs Standard Control Organization (CDSCO) under the aegis of Ministry of Health \& Family Welfare, Government of India. ${ }^{2}$ WHO-sponsored and World Bank-funded NPP for India was made operational from First January 2005. NPP is run by a network of peripheral, regional and zonal centers. These centers collect information and send to CDSCO, New Delhi. CDSCO analyses all information on Indian ADRs and finally send to International Uppsala Monitoring Center in Sweden. ${ }^{1-3}$

\section{PEDIATRICS- A MEDICAL BRANCH OF SPECIAL ATTENTION}

Most of the International and National programme are devoted to children because they share major area of vulnerable population. WHO introduce a separate model list of Essential Medicines (EML) in 2009 exclusively for the children, designated as WHO-EMLc. ${ }^{4}$ In view of their importance the Medical Council of India separate pediatrics from internal medicine in medical teaching curriculum.

\section{MEDICINE, CHILDREN \& ADRs}

Medicine is considered as more active and toxic in children due to specific age related pharmacological profile. Every year number of newer medicine is introduced in world market. Their long term safety profile may be uncertain in neonate and children. Someone suddenly disappear from the market after grave mishappening. Newer medicine with doubtful safety profile and availability of irrational fixed dose combinations (FDCs) are leading reasons behind adverse reactions in children. Their reporting system is not adequate due to lack of awareness, legal fear and poor advertisement etc.

\section{PHARMACOVIGILANCE- A HOPE FOR RATIONAL MEDICINE USE}

Adverse drug reactions (ADRs) are major and leading cause of morbidity and mortality in healthcare facilities worldwide. Pharmacovigilance, an emerging clinical discipline has aims to identifying new information about hazards associated with medicine and preventing harm to the person. ${ }^{1}$ Meanwhile it is not only confined with ADR reporting but its ultimate goal is to foster the rational and safe use of medicines. ${ }^{2-5}$

\section{SUB-UNIT - WHY?}

A new concept of pharmacovigilance in environmental pharmacology entitled as "pharmacoenvironmentology" 
was introduced in 2006. ${ }^{1}$ Even though pharmacovigilance is still in its infancy; it is not popular in India and limited with specific age group, but almost negligible in pediatrics.

\section{SUB-UNIT: TO \\ PHARMACOVIGILANCE}

STRENGTHEN

Pediatrics includes a wide range of life from neonate, infant, toddlers, children to adolescence. Each age group represent specific pharmacological profile such as indication, contraindication and adverse reaction etc. Therefore, for strengthening and its widespread application, there should be a sub division of pharmacovigilance for children i.e., "Pediatrics Pharmacovigilance". 5

\section{CONCLUSION}

Children are not to be considered as tiny adult. They show age dependent pharmacological profile. For widespread application in children, there should be a new sub-unit of pharmacovigilance i.e. "Pediatrics Pharmacovigilance".

\section{REFERENCES}

Available at http://en.wikipedia.org/wiki/Pharmacovigilance. Accessed 9 March 2011.

2. World Health Organization. Pharmacovigilance. Available http://www.who.int/medicines/areas/quality_safety/s afety_efficacy/pharmvigi/en/index.html. Accessed 9 March 2011.

3. Rajaseharan A. Pharmacovigilance: History, Need and Definition. Annual National Conference of the Society of Pharmacovigilance, India, SoPICon 2008,2-6.

4. World Health Organization. The WHO Model Lists of Essential Medicines-Model list for children. Available http://www.who.int/medicines/publications/essential medicines/en/. Accessed 9 March 2011.

5. Chaurasia RC. Rational phamacotherapeutic approach in therapeutic practices. Paper presentation at International conference on Rational use of Medicines, 27 November 2010, at LHMC, New Delhi, India. 